\title{
THE EFFECT OF COMPREHENSIVE TREATMENT OF PATIENTS WITH NON-ALCOHOLIC FATTY LIVER DISEASE IN COMBINATION WITH PREDIABETES ON THE LIPID PROFILE
}

DOI: 10.36740/WLek202104127

\author{
Vitalina V. Ivachevska \\ STATE HIGHER EDUCATIONAL ESTABLISHMENT «UZHHOROD NATIONAL UNIVERSITY», UZHHOROD, UKRAINE
}

\begin{abstract}
The aim: To evaluate the efficiency of the proposed therapy, which included recommendations for nutrition, physical activity and treatment with rosuvastatin, omega-3 PUFA and ursodeoxycholic acid, on the indicators of the lipid profile in patients with NAFLD and prediabetes.

Materials and methods: 78 patients with impaired glucose tolerance were examined. According to the inclusion and exclusion criteria, 55 patients with prediabetes and concomitant NAFLD were included in the study. All patients underwent a comprehensive clinical examination, which included anthropometric data collection, objective examination, and venous blood sampling for laboratory tests.

Results: The data obtained after 12 months of proposed treatment revealed a statistically significant improvement of indicators lipid profile in patients with prediabetes and NAFLD. Moreover, no significant difference between mean values of HDLC, LDLC, TG and atherogenic coefficient of almost healthy individuals and the corresponding indicators of treated patients detected.

Conclusions: therapy which included recommendations for nutrition, physical activity and treatment with rosuvastatin, omega-3 PUFA and ursodeoxycholic acid significantly improved lipid metabolism in patients with prediabetes and NAFLD.
\end{abstract}

KEY WORDS: non-alcoholic fatty liver disease, prediabetes, lipid metabolism, rosuvastatin, omega-3 PUFA and ursodeoxycholic acid

Wiad Lek. 2021;74(4):957-960

\section{INTRODUCTION}

Non-alcoholic fatty liver disease (NAFLD) is considered to be the most common cause of chronic liver disease worldwide $[1,2]$. In the general population the prevalence of NAFLD is about $20-30 \%$ [3], however, the prevalence is much higher in high-risk groups, which include obese people with type 2 diabetes mellitus, metabolic syndrome [4].

Data from epidemiological studies [3,5-8] confirm the tendency of increased incidence of NAFLD in patients with insulin resistance, which occurs in patients with obesity, type 2 diabetes and metabolic syndrome. While in the general population NAFLD is found in $30 \%$ [3], it reaches an impressive frequency among patients with grade I and grade II-III obesity - $75 \%[5,9,10]$ and $90 \%[7,8]$, respectively. NAFLD is found in $90 \%$ of patients with diabetes and hyperlipidemia [11].

NAFLD is very serious condition as it can lead to the development of non-alcoholic steatohepatitis (NASH) and unfortunately to cirrhosis, without the any signs and symptoms or changes of the liver enzymes. It was confirmed that patients with prediabetes and NAFLD are at higher risk of development of diabetes mellitus type 2 comparing with prediabetes patients without NAFLD [12].

It is common to see an increase of free fatty acids (FFA), low-density lipoprotein (LDL), and triglycerides (TG) as as a manifestation of dyslipidemia in patients with NAFLD. Such abnormalities of lipid metabolism cause inflammation, lipotoxicity, oxidative stress and as the result aggravate liver damage [13].

Interestingly, the prevalence of NAFLD among patients with prediabetes, as well as the features of metabolic disorders in this category of patients compared with patients with type 2 diabetes remain poorly studied. The question of the choice of treatment approach in patients with NAFLD and prediabetes also remains debatable.

\section{THE AIM}

To evaluate the efficiency of the proposed therapy, which included recommendations for nutrition, physical activity and treatment with rosuvastatin, omega-3 PUFA and ursodeoxycholic acid, on the indicators of the lipid profile in patients with NAFLD and prediabetes.

\section{MATERIALS AND METHODS}

On the basis of the therapeutic department of the State Enterprise "District clinical hospital of Uzhgorod station" State Territorial Branch Union (STBU) "Lviv railway" examined 78 patients with impaired glucose tolerance. Ac- 
cording to the inclusion and exclusion criteria, 55 patients with prediabetes and concomitant NAFLD were included in the study. The exclusion criteria were: age over 74 years; documented coronary heart disease; connective tissue disease; oncological diseases; the presence of complete left bundle branch block according to the ECG; type I and II diabetes mellitus; cirrhosis; previous viral hepatitis; toxic (alcohol - consumption of more than $40 \mathrm{~g}$ of ethanol /d), drugs (use of hepatotoxic drugs), severe metabolic liver disease; Wilson-Konovalov disease; autoimmune hepatitis; abrupt weight loss, parenteral nutrition for 2 weeks or more; chronic diseases of the gastrointestinal tract, accompanied by impaired absorption function (malabsorption syndrome); worm infestation; refusal of the patient to participate in this study.

Patients were divided into 2 groups, which were comparable in age, sex and stage of NAFLD. The division of patients into groups was performed in random order, by random numbers.

Because the initial examination of patients with prediabetes and NAFLD revealed that they belonged to the category of people at very high cardiovascular risk, all patients were prescribed rosuvastatin at a dose of $10 \mathrm{mg} / \mathrm{d}$. Thus, patients of group Ia $(\mathrm{n}=28)$ as hypolipidemic therapy received rosuvastatin $10 \mathrm{mg} / \mathrm{d}$ in combination with omega-3 PUFA at a dose of $1000 \mathrm{mg} / \mathrm{d}$ and ursodeoxycholic acid at a dose of $10 \mathrm{mg} / \mathrm{kg} / \mathrm{d}$.

Patients of group $\mathrm{Ib}(\mathrm{n}=27)$ were a comparison group and, except for rosuvastatin, did not take drugs. Patients in both groups followed dietary recommendations and performed 30-minute daily walks. For comparison, a control group of almost healthy individuals was used $(\mathrm{n}=$ 30). Evaluation of treatment efficacy was performed 6 and 12 months after the start of therapy.

All patients underwent a comprehensive clinical examination, which included anthropometric data collection, objective examination, and venous blood sampling for laboratory tests.

The method of ultrasound diagnosis of the liver was used to diagnose NAFLD, taking into account that ultrasound can detect an increase in liver echogenicity and confirm the diagnosis of NAFLD in conditions of fatty infiltration of the liver more than $33 \%$. Criteria for the presence of steatosis were considered to be a diffuse homogeneous increase in liver echogenicity ("white liver") with greater echogenicity than the right kidney (hepatorenal index) and dorsal attenuation of the ultrasound signal.

Statistical processing of the obtained results was performed on a personal computer using the software packages "Microsoft Office Excel 2003" and "Statsoft Statistica 8.0". The discrepancy was considered probable if the probability value was equal to or greater than $95 \%(\mathrm{p}<0.05)$.

\section{RESULTS}

During the study period among patients of group Ia who received complex treatment, there was a clear tendency to improve lipid metabolism (table I): the average value of total cholesterol significantly decreased after 12 months by $37.96 \%$ compared to baseline ( $\mathrm{p}<0.01)$ and $26.65 \%$ compared with data after 6 months $(\mathrm{p}=0.03)$. In addition, the average value of total cholesterol after 12 months in patients of group Ia was significantly lower than in almost healthy individuals $(p=0.02)$. The mean value of high-density lipoprotein (HDL) in patients of group Ia after 12 months significantly increased by $42.19 \%$ compared to baseline $(\mathrm{p}<0.01)$ and by $23.81 \%$ compared with the mean value after 6 months of treatment $(\mathrm{p}=0.01)$. The mean value of LDL levels significantly decreased after 12 months of treatment by $10.90 \%$ compared with the mean value before treatment $(\mathrm{p}<0.01)$.

Moreover, a significant difference between the mean values of HDL and LDL levels of almost healthy individuals and the corresponding indicators of patients of group Ia after 12 months was not detected ( $\mathrm{p}=0.19$ and $\mathrm{p}=0.49$, respectively). There was a significant decrease in the mean value of very low-density lipoprotein (VLDL) levels both after 12 months compared to baseline (by $12.21 \%$, p <0.01) and after 12 months compared with the average value after 6 months of treatment (by $9.45 \%, p) .=0.03$ ). The mean value of triglyceride level significantly decreased after 12 months of treatment by $40.23 \%(\mathrm{p}<0.01)$ compared to baseline and by $30.74 \%$ compared with 6 months $(\mathrm{p}=0.03)$.

Thus, due to the general tendency to improve lipid metabolism, patients in this group showed improvement of the atherogenic coefficient, namely: at the beginning of the study, this coefficient indicated a moderate risk of atherosclerosis, after 6 months of treatment, the atherogenic coefficient decreased significantly by $12.67 \%(\mathrm{p}<0.01)$, thus approaching normal.

After 12 months of treatment, the atherogenic coefficient decreased by $32.78 \%(\mathrm{p}<0.01)$ and was within normal levels, as evidenced by the lack of significant changes between its average value after 12 months and the average value of this ratio in healthy individuals (group III ) $(\mathrm{p}=0.07)$.

Among patients of group $\mathrm{Ib}$, statistically significant changes in the mean values of some indicators of lipid metabolism were found (table II). Thus, the average value of total cholesterol significantly decreased after 12 months of treatment by $17.60 \%$ compared to baseline $(\mathrm{p}<0.01)$ and by $14.46 \%$ compared with the average value of this indicator after 6 months of treatment $(\mathrm{p}<0,01)$. Moreover, the average value of total cholesterol after 12 months in patients of group Ib did not differ significantly from the average value of this indicator in almost healthy individuals $(p=0.16)$. No significant change was in the mean value of HDLC in patients of group $\mathrm{Ib}$ ( $\mathrm{p}>0.05$ ), while the average value of this indicator in patients of group Ib was significantly lower than in almost healthy individuals $(\mathrm{p}=0.01)$. No significant change was in the mean values of LDL and VLDL ( $p>0.05)$, as well as no significant difference was between the mean values of these indicators in patients of group Ib and persons in the control group $(\mathrm{p}=0.11$ and $\mathrm{p}=0.88$, respectively). During the study period, there was a significant decrease in the average value of triglycerides in patients of group Ib after 12 months by $15.31 \%(p=0.04)$, 
Table I. Dynamics of lipid profile of patients of group la during the treatment $(\mathrm{M} \pm \mathrm{m})$

\begin{tabular}{|c|c|c|c|c|c|c|c|c|}
\hline \multirow{3}{*}{ Indicators } & \multicolumn{4}{|c|}{ Group of comparisons } & \multicolumn{4}{|c|}{ Reliability indicator } \\
\hline & \multicolumn{3}{|c|}{ Group la $(n=28)$} & \multirow{2}{*}{$\begin{array}{c}\text { Control } \\
\text { group }(n=30)\end{array}$} & \multirow[b]{2}{*}{ p0-6 } & \multirow[b]{2}{*}{ p0-12 } & \multirow[b]{2}{*}{ p6-12 } & \multirow{2}{*}{$\begin{array}{c}\text { p12- } \\
\text { control } \\
\text { group }\end{array}$} \\
\hline & Baseline & $\begin{array}{l}\text { After } 6 \\
\text { months }\end{array}$ & $\begin{array}{l}\text { After } 12 \\
\text { months }\end{array}$ & & & & & \\
\hline Total Cholesterol & $5,19 \pm 1,06$ & $4,39 \pm 2,08$ & $3,22 \pm 1,72$ & $4,03 \pm 0,66$ & 0,08 & $<0,01^{*}$ & $0,03^{*}$ & $0,02^{*}$ \\
\hline HDLC & $1,28 \pm 0,36$ & $1,47 \pm 0,46$ & $1,82 \pm 0,42$ & $2,27 \pm 1,76$ & 0,09 & $<0,01^{*}$ & $0,01^{*}$ & 0,19 \\
\hline LDLC & $3,12 \pm 0,50$ & $3,03 \pm 0,58$ & $2,78 \pm 0,43$ & $2,71 \pm 0,34$ & 0,54 & $0,01^{*}$ & 0,07 & 0,49 \\
\hline VLDLC & $1,31 \pm 0,18$ & $1,27 \pm 0,24$ & $1,15 \pm 0,16$ & $0,83 \pm 0,13$ & 0,48 & $<0,01^{*}$ & $0,03^{*}$ & $<0,01^{*}$ \\
\hline TG & $3,43 \pm 1,38$ & $2,96 \pm 1,47$ & $2,05 \pm 1,54$ & $1,84 \pm 0,26$ & 0,22 & $<0,01^{*}$ & $0,03^{*}$ & 0,47 \\
\hline Atherogenic coefficient & $3,63 \pm 0,29$ & $3,14 \pm 0,58$ & $2,44 \pm 0,74$ & $2,15 \pm 0,43$ & $<0,01^{*}$ & $<0,01^{*}$ & $<0,01^{*}$ & 0,07 \\
\hline
\end{tabular}

n- number of patients; p0-6 - the significance of the difference of the indicators of patients in the relevant group before treatment and after 6 months p0-12 - the significance of the difference of the indicators of patients in the relevant group before treatment and after 12 months; p6-12 - the significance of the difference of the indicators of patients in the relevant group after 6 and 12 months of treatment; $p 12$-III - the significance of the difference between the patients of the corresponding group after 12 months of treatment and patients of control group; ${ }^{*}$ - statistically significant difference when comparing indicators in the dynamics.

Table II. Dynamics of lipid profile of patients of group lb during the treatment $(M \pm m)$

\begin{tabular}{|c|c|c|c|c|c|c|c|c|}
\hline \multirow{3}{*}{ Indicators } & \multicolumn{4}{|c|}{ Group of comparisons } & \multicolumn{4}{|c|}{ Reliability indicator } \\
\hline & \multicolumn{3}{|c|}{ Group Ib (n=27) } & \multirow{2}{*}{$\begin{array}{c}\text { Control } \\
\text { group }(n=30)\end{array}$} & \multirow[b]{2}{*}{ p0-6 } & \multirow[b]{2}{*}{ p0-12 } & \multirow[b]{2}{*}{ p6-12 } & \multirow{2}{*}{$\begin{array}{l}\text { p12- } \\
\text { contro } \\
\text { group }\end{array}$} \\
\hline & Baseline & $\begin{array}{l}\text { After } 6 \\
\text { month }\end{array}$ & $\begin{array}{l}\text { After } 12 \\
\text { month }\end{array}$ & & & & & \\
\hline Total Cholesterol & $5,17 \pm 1,07$ & $4,98 \pm 0,71$ & $4,26 \pm 0,54$ & $4,03 \pm 0,66$ & 0,46 & $<0,01^{*}$ & $<0,01^{*}$ & 0,16 \\
\hline HDLC & $1,17 \pm 0,34$ & $1,21 \pm 0,47$ & $1,23 \pm 0,39$ & $2,27 \pm 1,76$ & 0,72 & 0,55 & 0,87 & $0,01^{*}$ \\
\hline LDLC & $3,11 \pm 0,51$ & $3,08 \pm 1,24$ & $3,02 \pm 0,97$ & $2,71 \pm 0,34$ & 0,91 & 0,67 & 0,84 & 0,11 \\
\hline VLDLC & $0,77 \pm 0,14$ & $0,78 \pm 0,61$ & $0,81 \pm 0,72$ & $0,83 \pm 0,13$ & 0,94 & 0,78 & 0,87 & 0,88 \\
\hline TG & $4,18 \pm 1,44$ & $3,96 \pm 1,21$ & $3,54 \pm 0,61$ & $1,84 \pm 0,26$ & 0,55 & $0,04^{*}$ & 0,11 & $<0,01^{*}$ \\
\hline Atherogenic coefficient & $2,72 \pm 0,34$ & $2,60 \pm 0,49$ & $2,39 \pm 0,37$ & $2,15 \pm 0,43$ & 0,30 & $<0,01^{*}$ & 0,08 & $0,03^{*}$ \\
\hline
\end{tabular}

n- number of patients; $\mathrm{p} 0-6$ - the significance of the difference of the indicators of patients in the relevant group before treatment and after 6 months; p0-12 - the significance of the difference of the indicators of patients in the relevant group before treatment and after 12 months; p6-12 - the significance of the difference of the indicators of patients in the relevant group after 6 and 12 months of treatment; $p 12$-III - the significance of the difference between the patients of the corresponding group after 12 month of treatment and patients of control group; ${ }^{*}$ - statistically significant difference when comparing indicators in the dynamics.

but the average value of this indicator after 12 months was significantly higher than in almost healthy individuals $(\mathrm{p}<0,01)$. Like the mean triglyceride level, the mean value of atherogenic coefficient significantly decreased after 12 months compared to baseline by $12.13 \%$ ( $\mathrm{p}<0.01$ ), but remained significantly higher than in almost healthy individuals $(\mathrm{p}=0,03)$.

\section{DISCUSSION}

The results of many studies demonstrate the effectiveness of ursodeoxycholic acid, omega-3 PUFA and rosuvastatin in patients with NAFLD but independently of each other. For instance, scientists Anita Pathil, Gerhard Liebisch and co- authors, as well as E. B. Avalueva, E. I. Tkachenko and co-authors in their studies demonstrated a restoring altered lipid profiles of in patients with NAFLD which were treated with ursodeoxycholic acid $[14,15]$. Schohraya Spahis, Fernando Alvarez and co- authors showed beneficial effect of omega-3 fatty acids on liver steatosis and related metabolic abnormalities in obese children with NAFLD [16]. S. Antonopoulos and co-researchers in their work confirmed the positive effect of rosuvastatin on the course of non-alcoholic fatty liver disease [17]. At the same time, Srinivasan Dasarathy and others did not show a positive effect from the use of omega 3 fatty acids in diabetic patients with NAFLD [18]. In our study, we demonstrated for the first time the effectiveness of comprehensive treatment of NAFLD in prediabetes patients and its positive influence on lipid abnormalities.

\section{CONCLUSIONS}

Thus, it can be concluded that standard nutrition and physical activity recommendations, as well as treatment with rosuvastatin in patients with prediabetes was significantly effective, but did not provide complete correction of lipid metabolism. 
At the same time, proposed treatment, which included recommendations for nutrition, physical activity and treatment with rosuvastatin, omega-3 PUFA and ursodeoxycholic acid, demonstrated significant reduction in the mean values of total cholesterol and VLDL. As well as the lack of a statistically significant difference in the mean values of other indicators of lipid profile in patients with prediabetes and NAFLD compared with almost healthy individuals proves the efficacy of the proposed treatment in patients with prediabetes and NAFLD.

\section{REFERENCES}

1. Li B., Zhang Ch., Yu-Tao Zh.. Nonalcoholic Fatty Liver Disease Cirrhosis: A Review of Its Epidemiology, Risk Factors, Clinical Presentation, Diagnosis, Management, and Prognosis. Canadian Journal of Gastroenterology and Hepatology. 2018. doi.org/10.1155.

2. Wong V.W., Chu W.C., Wong G.L. et al. Prevalence of non-alcoholic fatty liver disease and advanced fibrosis in Hong Kong Chinese: a population study using proton-magnetic resonance spectroscopy and transient elastography. Gut. 2012;61:409-415.

3. Pais R., Barritt A.S. 4th., Calmus Y. et al. NAFLD and liver transplantation: Current burden and expected challenges. J Hepatol. 2016;65(6):12451257.doi: 10.1016.

4. Portillo-Sanchez P., Bril F., Maximos M. et al. High Prevalence of Nonalcoholic Fatty Liver Disease in Patients With Type 2 Diabetes Mellitus and Normal Plasma Aminotransferase Levels. J Clin Endocrinol Metab. 2015;100(6):2231-2238. doi:10.1210/jc.2015-1966.

5. Akbar D.H., Kawther A.H. Nonalcoholic fatty liver disease in Saudi type 2 diabetic subjects attending a medical outpatient clinic: Prevalence and general characteristics. Diabetes Care. 2003; (26):3351-3352.

6. Bellentani S., Saccoccio G., Masutti F. et al. Prevalence of and risk factors for hepatic steatosis in Northern Italy. Ann. Intern. Med. 2000; 132:112117.

7. Dixon J.B., Bhathal P.S., O'Brien P.E. Nonalcoholic fatty liver disease: Predictors of nonalcoholic steatohepatitis and liver fibrosis in the severely obese.Gastroenterology.2001;121:91-100.

8. Garcia-Monzon C., Martin-Perez E., lacono 0.L. et al. Characterization of pathogenic and prognostic factors of nonalcoholic steatohepatitis associated with obesity. Hepatol. 2000; 33:716-724.

9. de Costa G. A. et al . Non-alcoholic fatty liver disease (NAFLD) in different populations: A clinical and epidemiological study - sample of São José do Rio Preto. Rev. Assoc. Med. Bras. São Paulo. 2016;62(3):218-226.

10. Hazlehurst J.M., Woods C., Marjot T. et al. Non-alcoholic fatty liver disease and diabetes. Metabolism.2016;65(8):1096-1108. doi: 10.1016 /j.metabol. 2016.01.001.

11. Targher G., Day C.P., Bonora E. Risk of cardiovascular disease in patients with nonalcoholic fatty liver disease. N. Engl. J. Med. 2010;363:13411350.

12. Nishi T., Babazono A., Maeda T. et al. Evaluation of the fatty liver index as a predictor for the development of diabetes among insurance beneficiaries with prediabetes. J Diabetes Investig. 2014;6:309-316.
13. Pei K., Gui T., Kan D. et al. An Overview of Lipid Metabolism and Nonalcoholic Fatty Liver Disease. Biomed Res Int. 2020;4020249.

14. Pathil A., Liebisch G., Okun J.G. et al. Ursodeoxycholyl Lysophosphatidylethanolamide modifies aberrant lipid profiles in NAFLD. Eur J Clin Invest. 2015;45(9):925-31. doi: 10.1111/eci.12486.

15. Avalueva E.B., Tkachenko E.I., Skazyvaeva E.V. et al. Efficiency of ursodeoxycholic acid therapy in non-alcoholic fatty liver disease associated with metabolic syndrome. Eksp Klin Gastroenterol. 2013;(11):26-30.

16. Spahis S., Alvarez F., Ahmed N. et al. Non-alcoholic fatty liver disease severity and metabolic complications in obese children: impact of omega-3 fatty acids. J Nutr Biochem. 2018;58:28-36. doi: 10.1016/j. jnutbio.

17. Antonopoulos S., Mikros S., Mylonopoulou M. et al. Rosuvastatin as a novel treatment of nonalcoholic fatty liver disease in hyperlipidemic patients. Atherosclerosis. 2006; (84): 233-234.

18. Dasarathy S., Dasarathy J., Khiyami A. et al. Double-blind randomized placebo-controlled clinical trial of omega 3 fatty acids for the treatment of diabetic patients with nonalcoholic steatohepatitis. J Clin Gastroenterol. 2015;49(2):137-144.

The work was carried out in accordance with the plan of the research program of the Department of Therapy and Family Medicine of the Faculty of Postgraduate Education and Pre-University Training of Uzhhorod National University "Optimization of prevention and treatment of obesity and diabetes mellitus by Helicobacter pylori associated diseases", where the author is co-author.

\section{ORCID and contributionship:}

Vitalina V. Ivachevska: 0000-0002-2036-3568 ${ }^{A, B, C, D, E, F}$

\section{Conflict of interest:}

The Author declare no conflict of interest.

\section{CORRESPONDING AUTHOR Vitalina V. Ivachevska \\ Uzhhgorod National University \\ 148 Sobranetska st., 88015 Uzhhgorod, Ukraine \\ tel: +380506766803 \\ e-mail:vitalina.ivachevska@uzhnu.edu.ua}

Received: 10.10 .2020

Accepted:01.03.2021

A - Work concept and design, B - Data collection and analysis, C - Responsibility for statistical analysis, D-Writing the article, $\mathbf{E}$-Critical review, $\mathbf{F}$ - Final approval of the article 